\title{
Leukocyte adhesion deficiency type I - a focus on oral disease in a young child
}

\author{
Bhoom-Kantharaj Yashoda-Devi ${ }^{1}$, Nagaraj Rakesh ${ }^{2}$, Devaiah Devaraju ${ }^{3}$, Nataraj Santana ${ }^{4}$ \\ ${ }^{1}$ Professor and HOD \\ ${ }^{2}$ Senior lecturer \\ ${ }^{3}$ PG Student \\ ${ }^{4}$ Professor
}

Correspondence:

Dept of oral medicine, diagnosis and radiology

M.S.Ramaiah Dental College \& Hospital,

Msrit Post,

New Bel Road,

BANGALORE-560054

kal_devu@yahoo.co.in

Received: 03/03/2010

Accepted: 26/08/2010

\author{
Yashoda-Devi BK, Rakesh N, Devaraju D, Santana N. Leukocyte adhe- \\ sion deficiency type I - a focus on oral disease in a young child. Med Oral \\ Patol Oral Cir Bucal. 2011 Mar 1;16 (2):e153-7. \\ http://www.medicinaoral.com/medoralfree01/v16i2/medoralv16i2p153.pdf \\ Article Number: $16925 \quad$ http://www.medicinaoral.com/ \\ (C) Medicina Oral S. L. C.I.F. B 96689336 - pISSN 1698-4447 - eISSN: 1698-6946 \\ eMail: medicina@medicinaoral.com \\ Indexed in: \\ Science Citation Index Expanded \\ Journal Citation Reports \\ Index Medicus, MEDLINE, PubMed \\ Scopus, Embase and Emcare \\ Indice Médico Español
}

\begin{abstract}
This paper presents a case of the moderate form of Leukocyte adhesion deficiency type 1 (LAD-1) in a 4 year-old boy. LAD-1 is a rare, inherited immunodeficiency that affects 1 in 1 million people yearly. Affected patients are susceptible to recurrent bacterial and fungal infections, impaired pus formation and delayed wound healing. In the oral clinical finding, more important is a generalized prepuberal periodontitis that can affect the primary and permanent dentitions. For this reason cooperation between dentists and pediatricians is essential in these patients. Evaluating immune system in these patients included peripheral blood leukocyte counts, measurement of serum immunoglobulin levels, assessment of complement level and function, flow cytometric analysis of lymphocyte subsets, and tests of phagocytic function (nitrobluetetrazolium test (NBT)). In families with known molecular defect, an earlier prenatal diagnosis is possible by chorionic villi biopsy. The most important focus should be to control infections. Treatment includes systemic antibiotics and in many cases bone marrow transplantation.
\end{abstract}

Key words: Cellulitis, periodontitis, leukocyte, dental caries.

\section{Introduction}

Leukocyte adhesion deficiency (LAD) is a rare primary immunodeficiency disease (1). There are three types of LAD syndromes, LAD-I, II and III (also referred to as variant LAD-I) (2). LAD-I results from a mutation in the gene encoding the CD18 adhesion molecule. This mutation results in absent or severely reduced leukocyte cell surface expression of $\beta 2$ integrin molecules, which are essential to the adhesion of leukocytes to endothelial cells, transendothelial migration, and chemotaxis $(3,4)$. There is failure of innate host defenses against bacteria, fungi and other microorganisms resulting from defective adhesion and targeting of myeloid leukocytes to sites of microbial invasion (5). In type II, the primary genetic defect is in a specific Golgi GDP-fucose transporter leading to poor formation of CD15. It is characterized by recurrent infections, persistent leucocytosis, and severe mental and growth retardation. Type III is a 
rare disease with defects in the integrin activation process (mutation in kindling-3), and presents with both the immunodeficiency of LAD-I as well as severe bleeding disorders (6). Our patient, a 4 year-old boy with periodontitis as a manifestation of systemic diseases (Moderate LAD-I) and cellulitis. The purpose of this report is to stress the role of dentist in managing these medically compromised children.

\section{Case report}

A 4 year-old boy (Fig. 1) reported with a complaint of pain in his upper and lower jaw since one month and swelling in right lower jaw since one week. Pain was severe and radiating in nature. Patient was diagnosed as moderate LAD-I when he was 2 years of age and the past medical history revealed significant recurrent respiratory and gastrointestinal infections, starting from the time of birth necessitating three to four hospitalizations per year. The patient was a full term baby, born to second degree consanguineous parents. The two elder siblings died at 3 months and 2 months, but the cause of their death is unknown. Generally there is a history of delayed umbilical separation, but was absent in our case. Patients with the moderate phenotype are usually diagnosed later in life and do not typically have delayed umbilical cord separation.

General physical examination revealed that the patient was moderately built and poorly nourished, conscious, oriented and cooperative. Pallor was positive and bilateral submandibular lymph nodes were palpable, tender, firm in consistency, and movable. On presentation, patient was febrile and a firm, tender extraoral swelling was evident on the right lower third of the face. The facial skin demonstrated hyper and hypo pigmented patches and the skin appeared scaly and dry, especially around the nose and mouth characteristic of eczema. The lips were chapped and swollen with white fissures at the angle of mouth, suggestive of candidiasis. Examination of other cutaneous sites revealed large scar on the scalp and left elbow.

Intraorally (Fig. 2), there was generalized mobility of teeth and multiple carious teeth in anterior maxilla and posterior mandible. Caries was due to the neglected oral hygiene, since patient was scared of bleeding upon brushing his teeth. Caries is not typical of this disease. Gingival examination revealed generalized inflammation which was diffuse involving marginal, interdental and attached gingiva. Generalized enlargement of marginal and interdental gingiva was noted and was more lingually. Grade III bleeding on probing was present. Probing depth was in the range of $7-8 \mathrm{~mm}$ and clinical attachment level (CAL) was in the range of 5-7 $\mathrm{mm}$, and examination of tongue revealed benign migratory glossitis. There was enlargement of palatine tonsils.

Panoramic radiograph (Fig. 3) revealed severe general-

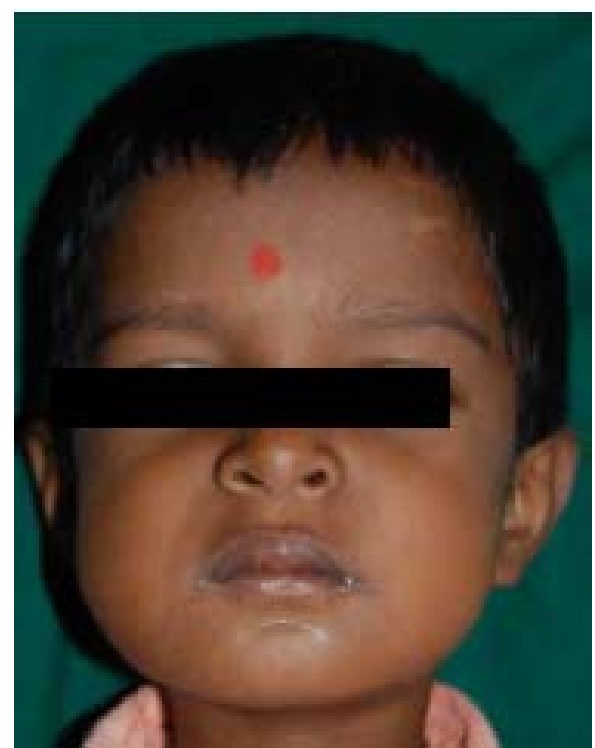

Fig. 1. Patient photograph showing diffuse swelling on the right lower third of face.

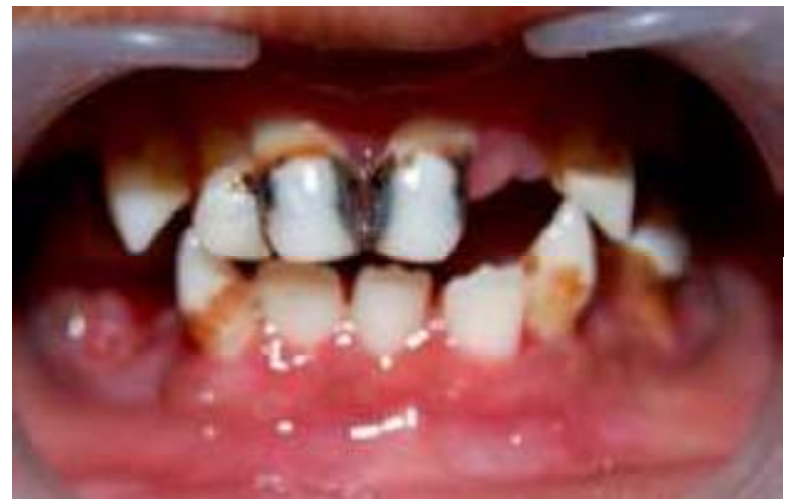

Fig. 2. Intraoral photograph.

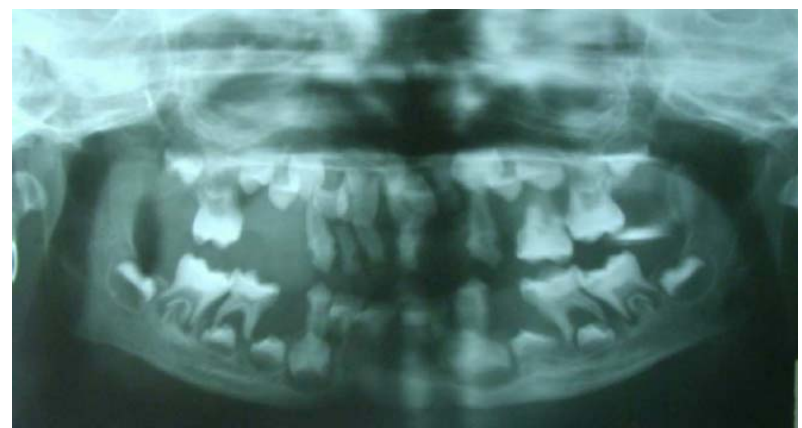

Fig. 3. Preoperative Panoramic radiograph showing severe generalized alveolar bone loss. 
Table 1. Laboratory values.

\begin{tabular}{|c|c|c|}
\hline Hematological investigations & Reported value & Reference intervals \\
\hline Hemoglobin & $8.9 \mathrm{gm} / \mathrm{dL}$ & $14.5 \mathrm{gm} / \mathrm{dL}$ \\
\hline \multicolumn{3}{|l|}{ CBC profile } \\
\hline Total WBC count & 35200/microlitre & $4000-11000$ \\
\hline Neutrophils & $56 \%$ & $40-74$ \\
\hline Lymphocytes & $38 \%$ & $20-40$ \\
\hline Eosinophils & $04 \%$ & $1-7$ \\
\hline Monocytes & $02 \%$ & $1-9$ \\
\hline Platelet count & $585000 / \mathrm{mm}^{3}$ & $1.5-4.5$ \\
\hline $\mathrm{MCV}$ & $64.8 \mathrm{fL}$ & $80-100$ \\
\hline $\mathrm{MCH}$ & $20.0 \mathrm{PG}$ & $27-31$ \\
\hline $\mathrm{MCHC}$ & $30.9 \mathrm{G} / \mathrm{dL}$ & $32-36$ \\
\hline RDW & $20.4 \%$ & $11-15$ \\
\hline ESR & $55 \mathrm{~mm} / \mathrm{hr}$ & $0-9$ \\
\hline \multicolumn{3}{|l|}{ Immunoglobulin } \\
\hline $\operatorname{lgG}$ & 3069 mg\% & $206-601$ \\
\hline $\lg A$ & $479 \mathrm{mg} \%$ & $28-47$ \\
\hline $\operatorname{lgM}$ & $111 \mathrm{mg} \%$ & $17-105$ \\
\hline Bone marrow & \multicolumn{2}{|c|}{$\begin{array}{l}\text { Solidly cellular marrow with mild myeloid hyperplasia and } \\
\text { non specific reactive changes. }\end{array}$} \\
\hline Biopsy & \multicolumn{2}{|c|}{$\begin{array}{l}\text { Scanty mainly subcortical marrow with no significant lesion } \\
\text { by trephine biopsy. }\end{array}$} \\
\hline $\mathrm{LDH}$ & $433 \mathrm{U} / \mathrm{L}$ & $150-300$ \\
\hline Creatinine & $0.5 \mathrm{mg} \%$ & $0.6-1.3$ \\
\hline \multicolumn{3}{|l|}{ Serum Calcium \& Phosphate } \\
\hline Calcium & $9.4 \mathrm{mg} / \mathrm{dL}$ & $9-11.5$ \\
\hline Phosphorus & $5.4 \mathrm{mg} / \mathrm{dL}$ & $4.5-6$ \\
\hline \multicolumn{3}{|l|}{ Liver function tests } \\
\hline Albumin & 3.5 gm\% & $3.4-5$ \\
\hline SGOT & $32 \mathrm{U} / \mathrm{L}$ & $15-37$ \\
\hline SGPT & $12 \mathrm{U} / \mathrm{L}$ & $30-65$ \\
\hline Alkaline phosphatase & $195 \mathrm{U} / \mathrm{L}$ & $50-136$ \\
\hline Serum potassium & $3.5 \mathrm{~m} \mathrm{~mol} / \mathrm{L}$ & $3.7-5.2$ \\
\hline \multicolumn{3}{|l|}{ Blood borne virus screen } \\
\hline HIV & & - \\
\hline $\mathrm{HbsAg}$ & & - \\
\hline $\mathrm{HCV}$ & & - \\
\hline \multicolumn{3}{|c|}{ CD11a- 2.32\%, CD11b- 8.7\%, CD11c- 9.4\% } \\
\hline \multicolumn{3}{|c|}{ CD3- 58.5\%, CD4- 45.4\%, CD8- 16.5\%, CD19- 9.8\% (normal) } \\
\hline Bombay blood group antigen & \multicolumn{2}{|l|}{ Absent } \\
\hline Peripheral smear & \multicolumn{2}{|c|}{ Microcytic hypochromic anemia } \\
\hline
\end{tabular}

ized alveolar bone loss giving a floating tooth appearance. Laboratory values of our case are tabulated (Table 1). Bombay blood group was absent in our case, which is usually present in LAD-II.

The final diagnosis of periodontitis as a manifestation of systemic disease and cellulitis due to LAD type I was given based on the history, clinical features and investigatory reports. Patient was admitted and treated with injection Cefepime $500 \mathrm{mg}$ and injection Amikacin 75 mg intravenously BD and syrup Crocin (acetaminophen) $120 \mathrm{mg} / 5 \mathrm{ml}$ was advised to be taken orally, as required for 10 days. After controlling the infection, we recorded patient's hygiene performance index (Podshadley A.G and Haley. J.V 1965) which was fair (score-3.1) and gingival index (Leo.H and Silness.J 1963) which was severe (score-2.8). Scaling and root planning was performed 
and severely mobile mandibular right primary second molar and maxillary left primary second molar teeth were extracted followed by primary closure of gingival tissues. Antiseptic mouthwash (Chlorhexidine-0.12\%) was prescribed and fluoride application was done (APF gel).

Oral health regimen for follow up: Patient is under periodic examination (every 3 months). During examination, we subjected the patient for oral and general physical examination. Professional oral prophylaxis was done after recording hygiene performance index, gingival index, probing depth and CAL. Parents were counseled to provide a nutritious diet to the child and were advised to take care of the skin and mucous membrane to protect against injury. Parent counseling, oral hygiene instruction included brushing his teeth twice daily and antiseptic mouth rinse after every meal. We administered a dose of amoxicillin $(5 \mathrm{mg} / \mathrm{kg}) 2 \mathrm{hrs}$ before dental treatment and continued this prophylaxis twice a day for the next 2 days.

Panoramic radiographs were taken yearly with no progressive bone loss in the first year. There was spontaneous exfoliation of $31,51,52,53,61,62,75$ and 83. Panoramic radiograph taken during second year of follow up revealed increased alveolar bone level; especially in the mandibular premolar region.

There was significant improvement in his oral health and decrease incidence of oral infections; especially abscesses and facial swelling during second year follow up. Patient was admitted in our hospital and treated thrice in two years for respiratory infection, but did not develop orofacial infections in this period. We noticed bilateral submandibular lymph node enlargement twice in his follow up visits. At present he is under regular follow up.

\section{Discussion}

Leukocyte adhesion deficiency type I was first described as a separate entity among immunodeficiencies in 1979 by Kuijpers et al. (7). Since then number of case reports are published, with few reports on oral manifestations and management of oral infections. LAD-I is a rare, inherited, autosomal recessive, immunodeficiency disease caused by the combined loss of expression on the surface of leukocytes of the leukocyte integrins LFA-1, Mac-1, and pl50, 95 (8). It usually presents in infancy or early childhood, with recurrent life-threatening bacterial infections, impaired pus formation, and wound healing $(9,10)$. Two relatively distinct clinical phenotypes of LAD I have been described. Based on degree of expression, the disease was subdivided into severe $(<1 \%$ expression of CD18) and moderate $(1-30 \%$ expression of CD18) phenotypes (11).

Patients with the severe form of the disease tend to succumb early in life to overwhelming infection, whereas, those with a moderate form of the disease often survive through it to adulthood (12). Oral candidiasis is also a frequently observed symptom and must be treated aggressively (13).

The diagnosis of LAD I was based on typical clinical presentation including recurrent severe infections, impaired pus formation, impaired wound healing, combined with laboratory demonstration of leukocytosis, significant reduction (moderate phenotype) or near absence (severe phenotype) of CD18 and its associated molecules CD11a, CD11b, CD11c on leukocytes.

Therapeutic strategies in these patients should concentrate on prevention of local (dental) and systemic infections. Teeth must be preserved whenever possible, and periodontal disease should be controlled with periodic oral prophylaxis for the sake of maintaining normal physical and psychologic development of the child (3). Hematopoietic stem cell transplantations are gold standard therapies and have a very high success rate. However, retroviral mediated gene replacement may be the treatment of the future because; a low level of correction of expression of $\beta 2$ would provide clinical benefits. Roberts et al. (14) conducted a 5-year case study of a child with LAD I, described the generalized progressive periodontitis and intraoral infections and concluded that the associated therapeutic challenges used in the attempts to arrest the periodontal disease were largely unsuccessful, but in our case there was a improvement in his periodontal condition.

We noticed significant improvement in alveolar bone level which was mainly due to the strict oral health regimen, control of infection and extraction of the offending teeth. This tissue condition allowed alveolar bone development around tooth follicle during odontogenesis. We recommend extraction of offending teeth, but not all the mobile teeth. Since there is early alveolar bone loss, there will be generalized mobility. Clinician should thoroughly examine and advice extraction of offending teeth which causes repeated infection, following up with oral health regimen. Finally, oral swabs and blood cultures should be performed in cases of LAD-I when there is any episode of suspected infection, so that optimal measures can be taken through the use of appropriate antibiotics.

\section{References References with links to Crossref-DOI}

1. Bonilla FA, Bernstein IL, Khan DA, Ballas ZK, Chinen J, Frank $\mathrm{MM}$, et al. Practice parameter for the diagnosis and management of primary immunodeficiency. Ann Allergy Asthma Immunol. 2005;94:S1-63.

2. Etzioni A. Leukocyte adhesion deficiencies: molecular basis, clinical findings, and therapeutic options. Adv Exp Med Biol. 2007;601:51-60.

3. Majorana A, Notarangelo LD, Savoldi E, Gastaldi G, LozadaNur F. Leukocyte adhesion deficiency in a child with severe oral involvement. Oral Surg Oral Med Oral Pathol Oral Radiol Endod. 1999;87:691-4. 
4. Paller AS, Nanda V, Spates C, O'Gorman M. Leukocyte adhesion deficiency: recurrent childhood skin infections. J Am Acad Dermatol. 1994;31:316-9.

5. Bunting M, Harris ES, McIntyre TM, Prescott SM, Zimmerman GA. Leukocyte adhesion deficiency syndromes: adhesion and tethering defects involving beta 2 integrins and selectin ligands. Curr Opin Hematol. 2002;9:30-5.

6. Abram CL, Lowell CA. Leukocyte adhesion deficiency syndrome: a controversy solved. Immunol Cell Biol. 2009;87:440-2.

7. Kuijpers TW, Van Lier RA, Hamann D, de Boer M, Thung LY, Weening RS, et al. Leukocyte adhesion deficiency type 1 (LAD-1)/ variant. A novel immunodeficiency syndrome characterized by dysfunctional beta2 integrins. J Clin Invest. 1997;100:1725-33.

8. Wardlaw AJ, Hibbs ML, Stacker SA, Springer TA. Distinct mutations in two patients with leukocyte adhesion deficiency and their functional correlates. J Exp Med. 1990;172:335-45.

9. Watanabe K. Prepubertal periodontitis: a review of diagnostic criteria, pathogenesis, and differential diagnosis. J Periodontal Res. 1990;25:31-48

10. Bowen TJ, Ochs HD, Altman LC, Price TH, Van Epps DE, Brautigan DL, et al. Severe recurrent bacterial infections associated with defective adherence and chemotaxis in two patients with neutrophils deficient in a cell-associated glycoprotein. J Pediatr. 1982;101:93240.

11. Etzioni A, Alon R. Leukocyte adhesion deficiency III: a group of integrin activation defects in hematopoietic lineage cells. Curr Opin Allergy Clin Immunol. 2004:4:485-90.

12. Movahedi M, Entezari N, Pourpak Z, Mamishi S, Chavoshzadeh $\mathrm{Z}$, Gharagozlou M, et al. Clinical and laboratory findings in Iranian patients with leukocyte adhesion deficiency (study of 15 cases). J Clin Immunol. 2007;27:302-7.

13. Cox DP, Weathers DR. Leukocyte adhesion deficiency type 1: an important consideration in the clinical differential diagnosis of prepubertal periodontitis. A case report and review of the literature. Oral Surg Oral Med Oral Pathol Oral Radiol Endod. 2008;105:8690 .

14. Roberts MW, Atkinson JC. Oral manifestations associated with leukocyte adhesion deficiency: a five-year case study. Pediatr Dent. 1990;12:107-11. 